\title{
Olfactory dining: designing for the dominant sense
}

\author{
Charles Spence $^{1 *}$ and Jozef Youssef ${ }^{2}$
}

\begin{abstract}
The majority of researchers agree that olfactory cues play a dominant role in our perception and enjoyment of the taste (or rather flavour) of food and drink. It is no surprise then that in recent years, a variety of modern (or dare we say it, modernist) solutions have been developed with the explicit aim of delivering an enhanced olfactory input to the diners/dishes served in the restaurant, and occasionally also in the home setting too. Such innovations include everything from aromatic cutlery and plateware through to the use of atomizers and dry ice. A few augmented reality (AR; i.e. an experience of a physical, real-world environment whose elements have been augmented, or supplemented, by computer-generated sensory input) solutions have also made their way out from well-funded technology labs, and scent-enabled plug-ins for mobile devices are slowly being commercialized. The latter could potentially be used to enhance the orthonasal olfactory component of our multisensory food experiences in the years to come. Ultimately, though, there is an important question here as to the authenticity of those food and flavour experiences that have been augmented/enhanced by aroma and fragrance cues that are not integral to the food or drink itself. It is this lack of authenticity that may, at least in your authors' humble opinion, limit the more widespread uptake of such a sense-by-sense approach to the contemporary construction of multisensory gastronomic experiences. The challenge, as always, remains to find the unique selling point (USP) of such approaches to olfactory stimulation, over and above their mere feasibility and inherent theatricality.
\end{abstract}

Keywords: Taste, Flavour, Olfaction, Multisensory, Olfactory dining, Orthonasal, Authenticity, Technology

A man eats nothing without smelling it more or less consciously, while with unknown foods his nose acts always as the first sentinel, crying out Who goes there? When the sense of smell is cut off, taste itself is paralyzed... ([1], p. 49).

In brief, we will be remembered by the smell of the food we serve to people: let's make sure that their recollection is a pleasant one! [2]

\section{Review}

One of the most pervasive claims to be found in the food science literature, as well as in the plethora of press articles written about food and flavour, is that somewhere between $75-95 \%$ of what we think of as taste (i.e.

\footnotetext{
* Correspondence: charles.spence@psy.ox.ac.uk

${ }^{1}$ Crossmodal Research Laboratory, Department of Experimental Psychology, Oxford University, Oxford OX1 3UD, UK

Full list of author information is available at the end of the article
}

as coming from the tongue) is actually transduced by the olfactory receptors in the nose instead. Just take the following as a representative example: 'If people are asked to select which sense they find least important, the sense of smell is routinely regarded as the least important of the five', according to Martin ([3], p. 60). He continues as follows: 'It is, in fact, responsible for 80 percent of food flavour, a fact that is largely unknown and elicits a degree of disbelief'. Now, as stressed by Spence [4] recently in this journal, delivering a precise, quantitative figure concerning olfaction's relative contribution to multisensory flavour perception may not be possible, especially given the difficulty associated with trying to define flavour in the first place [5]. Nevertheless, that said, what the majority of contemporary researchers do broadly seem to agree upon is the fact that it plays a dominant role in flavour perception, not to mention olfaction's role more generally in our enjoyment of food and drink (and in the setting of flavour expectations). Given such agreement amongst researchers, the 
questions that we wish to address here are: (1) How is such knowledge being incorporated into, and hence changing, contemporary culinary practice? And (2) are there any dangers/limitations associated with this approach to augmenting the experience of dining?

Orthonasal olfaction ${ }^{1}$ is perhaps the most important sense (along with vision) in terms of setting our expectations about a dish (and building-up our anticipation; see [6] for a review). However, that said, oftentimes the way that the dishes are served in the restaurant, or home dining environment (think microwavable processed meals), simply is not optimized to make the most of the olfactory element in a dish $[7,8]$. Indeed, one point to draw attention to here concerns the difference between those meals that are cooked at home (excluding microwave and other ready meals of course) and a restaurant meal in terms of the surrounding smell/smell of the environment. When cooking at home, it is likely that the food and cooking smells will play a role in helping the diners to anticipate and expect the flavours to come. This will likely also help to get their saliva going in preparation of the delivery of the food. In a restaurant, which is separated from the dining area (and/or when coupled with a good extraction system), such aromas cannot play this role (albeit this largely being an intentional decision since the diners will be eating different things at different times so ambient smells may be distracting). Thus, while the cloche in some sense traditionally played the role of trying to recreate these aromas at the table, as this form of silverware steadily moves further and further out of fashion (and with little sign of ever coming back into fashion), one might consider whether the various new methods of delivering orthonasal stimuli discussed in this article are not perhaps being used to try and make up/compensate for this? While this might be a part of the story, as we will see below, there is actually a lot more going on here in terms of using aromas and scents to trigger moods, emotions, memories, nostalgia etc. (see also http://www.ritzcarlton.com/en/Properties/ Berlin/Dining/Fragrances/Default.htm).

Of course, beyond the orthonasal hit of aroma we get on first sniffing a dish, volatiles are going to be released during the very act of consumption too (and experienced retronasally $[9,10])$. As such, one might want to ask whether orthonasal olfaction really does play such a dominant role in terms of setting our subsequent flavour experiences. We would argue that it does, since orthonasal olfactory cues give rise to 'flavour expectations' that, in turn, anchor the subsequent flavour experience (see $[6,11])$.

\section{Capturing aroma}

Looking back, one's mind might well be drawn to the cloche, the silver dish cover found in many a very traditional European restaurant that helps a dish to retain its heat on its way from the kitchen, ${ }^{2}$ until the more-or-less theatrical 'reveal' at the table (see Fig. 1). Although rarely mentioned, such a piece of serviceware presumably also functioned to keep the aromas of the food trapped under the hood until the appropriate moment. It is perhaps worth noting that in today's climate of plating for the eye (see [12] for a review), what the cloche delivers in terms of surprise (and tradition; the cloche apparently going out of vogue with traditional 'silver service'), it loses in terms of eye (or visual) appeal. The fact that the dish is hidden from the diners' view until the very last moment is perhaps not the ideal way to retain a dish's aroma in today's image-obsessed age (the terms gastroporn, or food porn, come to mind here). Furthermore, it may also be important to bear in mind the latest findings highlighting the importance of the correct orientation of the plate in the restaurant to how much the diner enjoys their food and how much they would be willing to pay for certain dishes [13, 14]. Obviously, it is going to be hard for the waiter to get the precise alignment of the dish right without being able to see the food itself when laying the cloche-covered plate before the diner. What is more, nowadays, the very sight of the cloche in the dining room is unavoidably associated with a certain sort of traditional restaurant, an association that does not necessarily gel all that well with the contemporary restaurant landscape.

If the olfactory element is as important to the diner's enjoyment of a dish as the scientists and media would have us all believe (see [4] for a review), one might expect that chefs would be designing their food experiences to make the most of the olfactory component. Indeed, one obvious solution here is just to simply

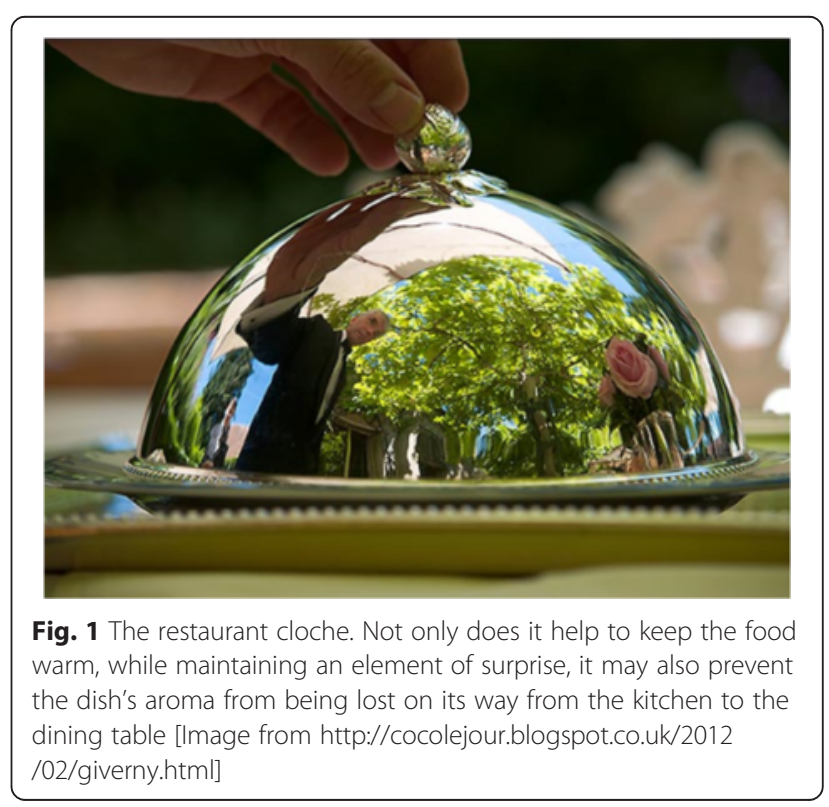


concentrate the aromas of the dish itself, and that is certainly what some chefs are doing. As Nassauer [15] noted recently, "Restaurants are adjusting recipes to make aromas more concentrated and pleasant." 3 Though, quite how the restaurants were going about doing this was not made clear in the newspaper report itself. In this article, though, we are going to take a closer look at some of the more innovative ways in which chefs and culinary artists have been playing with accentuating the olfactory component of the dining (and drinking) experiences that they provide to their customers, whoever, and wherever, they might be.

As we will see below, the last few years have seen the emergence of a number of innovative solutions to the delivery of an enhanced olfactory element to the table: Everything from aromatic plateware and aromatic cutlery to atomizers (to spray aroma over the meal, and as we will see, possibly over the diner as well), digital olfaction (involving both AR and scent-enabled plug-ins) and smell-enhancing attire as well-all of it has made an appearance somewhere, be it restaurant, experimental dinner or science lab in recent years.

\section{Designing dishes to enhance the olfactory hit The 'smoking' cloche}

One intriguing dish that can, in some ways, be seen as a modern take on the traditional silver version comes from chef Jozef Youssef's dining concept Synaesthesia (see https://kitchen-theory.com/). In this case, a bowl of corn risotto, sous vide guinea fowl, miso-cured egg yolk and chive powder is placed in a smoke-filled clear plastic bag in front of each of the diners sitting around a long table (see Fig. 2). The chef would emerges from the kitchen and dramatically slice through each bag, in turn, using a sharp knife. As the bag is sliced open, the smoky aroma inside is suddenly released. At the same time, the plate of food is itself revealed visually to the diner through the mist. After this olfactorily enhanced 'reveal', the chef then carefully dribbles ${ }^{4}$ a little dark and aromatic sauce (guinea fowl and shiitake jus) over the dish. Only then is the food ready to eat. In this case, notice how the sealed bag in which the dish is presented not only preserves the smoky aroma for the benefit of the diner's nostrils but also helps to smoke the food (thus serving a functional purpose, as well as bringing a memorable, ${ }^{5}$ and quite possibly theatrical, element to the proceedings).

\section{Olfactory-enhanced plateware}

In fact, in recent years, a number of chefs around the world have been experimenting with aromatic plateware. Many of the most innovative examples in this space have emerged from chef Grant Achatz's Chicago kitchen, Alinea (https://website.alinearestaurant.com/). In one case,

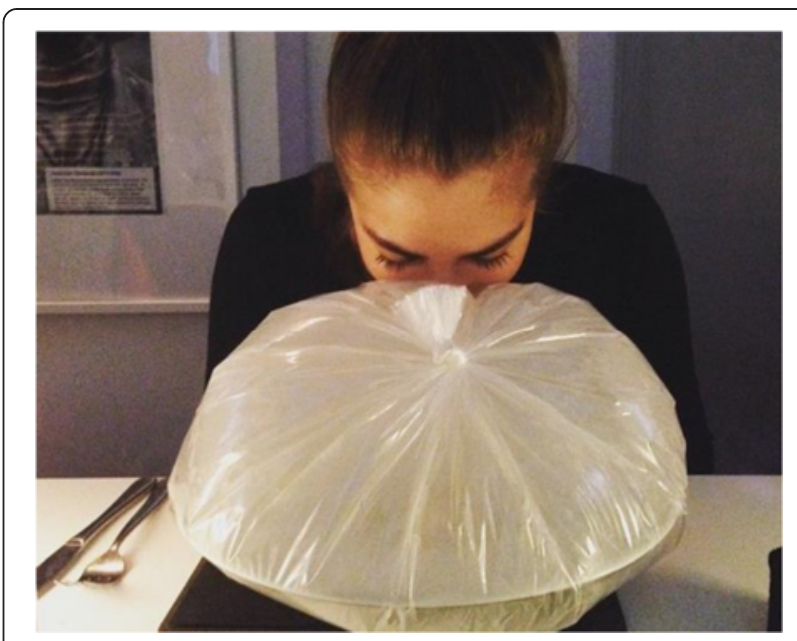

Fig. 2 'Born in Papua New Guinea'. A dish of guinea fowl, sweet corn risotto, miso-cured yolk served in a bag served by chef Jozef Youssef, as part of the Synaesthesia dining concept. The bag is filled with a smoky aroma in the kitchen and brought to the table as shown. After the bagged dishes have all been placed on the table, the chef emerges from the kitchen, slices open the bags with a knife and drizzles some dark sauce onto the dish

a bowl of food is placed atop a larger dish containing hyacinths in front of the diner. The waiter would then pour hot water over the flowers at the table in order to release their scent prior to the diner consuming the dish. Notice once again the targeted delivery of scent at the table. In another distinctive example of Achatz's creative use of scented plateware, the waiter would first place an air-filled pillow in front of the diner and then carefully place an oversized bowl of food on top of it (e.g. an English-peas-and-ham preparation; [16]). As the diner interacts with their food, the pillow slowly starts (perhaps unexpectedly for the diner) to release a stream of lavender-scented air. Here, while the food itself is undoubtedly worthy in its own right, it is the integration of the dish with the aromatics of the 'plateware' (and the ensuing spectacle, not to mention surprise) ${ }^{6}$ that once again helps to deliver a truly memorable multisensory dining experience.

One thing to note here is how the orthonasal aroma is sometimes used to evoke memories in the diner. Here, one can think of Achatz's use of burning oak leaves, designed to evoke memories of childhood and served with pheasant, shallot, and cider gel [17], or chef Heston Blumenthal's use of the scent of the sweetshop to remind diners of pleasant memories from their childhood (and perhaps to induce a sense of nostalgia).

Another intriguing olfactory example comes from design studio Blanch $\mathcal{E}$ Shock (http://blanchandshock.com/). They serve duck with Jerusalem artichokes and melilot on a 'plate' of charred chestnut wood. In this case, it is the charring of the plateware 
itself that helps to give the dish such an intense aroma (see Fig. 3). Something very similar has been going on at Noma (http://noma.dk/), the worldfamous restaurant in Copenhagen (and voted the world's best for 3 years over the last decade). For a while, diners would be served a dish of two small quail eggs sitting atop a bed of smoking straw [18]. Notice how what all of these diverse examples have in common is the use of the plateware either to capture and retain, or else to deliver, an enhanced aroma hit direct to the diner's nostrils. Another increasingly popular approach to delivering an additional olfactory component comes from those who have been experimenting with aroma-enhancing cutlery.

\section{Olfactory-enhanced cutlery}

In recent years, various individuals and companies have developed a range of novel designs for cutlery; designs that are capable of providing an extra olfactory component to every fork or spoonful of food. Louise Bloor, of the Fragrant Supper Club in London (http://www.louisebloor.com/), for example, uses wooden forks whose handles her diners are encouraged to scent with a range of aromas. Just imagine yourself, for example, eating a plain ice cream, with a wooden spoon that has been scented with raspberry or bergamot essential oil. A slightly more high-tech version of essentially the same idea comes from Canadian company Molecule- $\mathrm{R}$ Inc. with their 'Aromafork' (see http://www.molecule-r.com/). In the

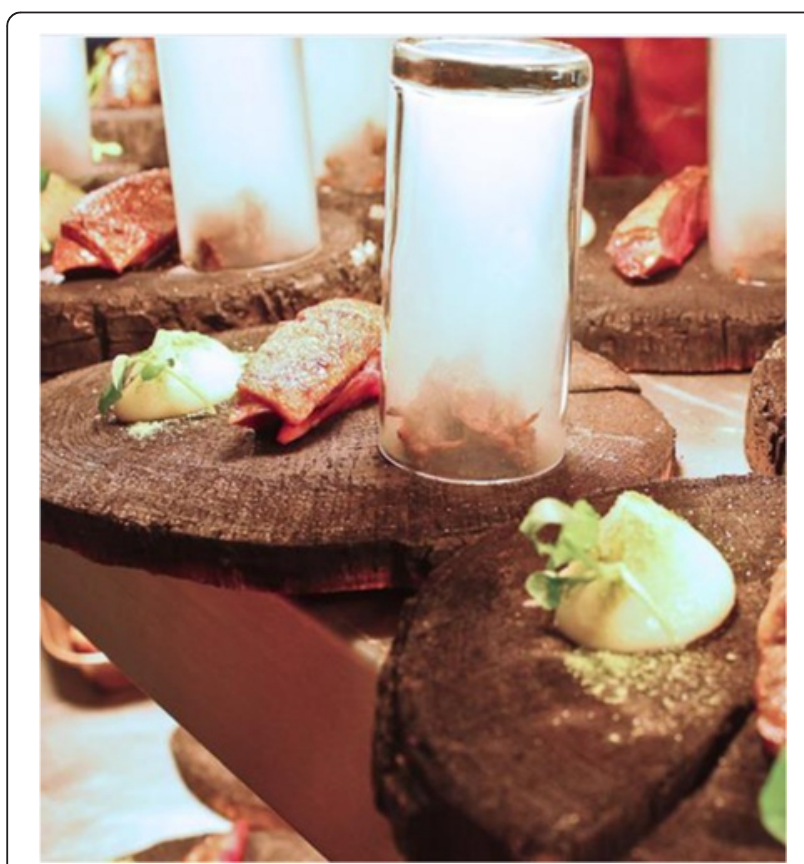

Fig. 3 An example of olfactorily enhanced plateware. A Blanch \& Shock dish served on a burnt piece of wood [Reproduced with permission of Josh Pollen, Blanch and Shock, London] latter case, the diner (or cook working the kitchen) is supposed to use the pipette of 'liquid aroma' provided to apply scent to a small piece of blotting paper inserted into the mid-section of the cutlery (see Fig. 4).

The media coverage around this, now commerciallyavailable, range of cutlery has focused primarily on the home cook who just so happens to have forgotten to add a key ingredient to whatever dish they happen to be creating (e.g., see [19]). For us, though, it is the opportunity to design enhanced olfactory-dining experiences that such cutlery might offer that would seem so much more intriguing than merely making up for the chef's absent-minded mistakes. Currently, the Aromafork comes with 21 different flavours, including chocolate, vanilla, lychee, basil, etc. ${ }^{7}$ One thing the company seems to have forgotten, however, is the importance of matching the knife and fork-as thus far only forks are provided. While there is obviously little need to scent the knife itself (since it rarely comes close to the mouth, at least not in polite company), it is normally deemed desirable to have one's cutlery match. ${ }^{8}$ Over in Australia, Elizabeth Willing has also designed a set of porous ceramic spoons that are capable of releasing aroma (see Fig. 5).

It should, though, be noted that the design solutions here need not be especially high-tech; think only of inserting some fresh herbs into the handle of one's cutlery as, for example, done with the sprig of fragrant thyme inserted into the curly wire-handled cutlery used at Moto in Chicago (http://motorestaurant.com/) when serving 'flat'-ware with Toro and Caviar (see Fig. 6) (Flatware, a North American term for eating utensils such as knives, forks and spoons, which can also be used to describe relatively flat dishes such as plates and saucers). Similarly, designer Luki Huber created a spoon for the elBulli restaurant that had an integrated clip in the handle to allow the fresh herbs to be clipped just next to the bowl and the spoon, thereby once again providing a complementary aroma with each and every spoonful that the diner takes. And before moving on, we should

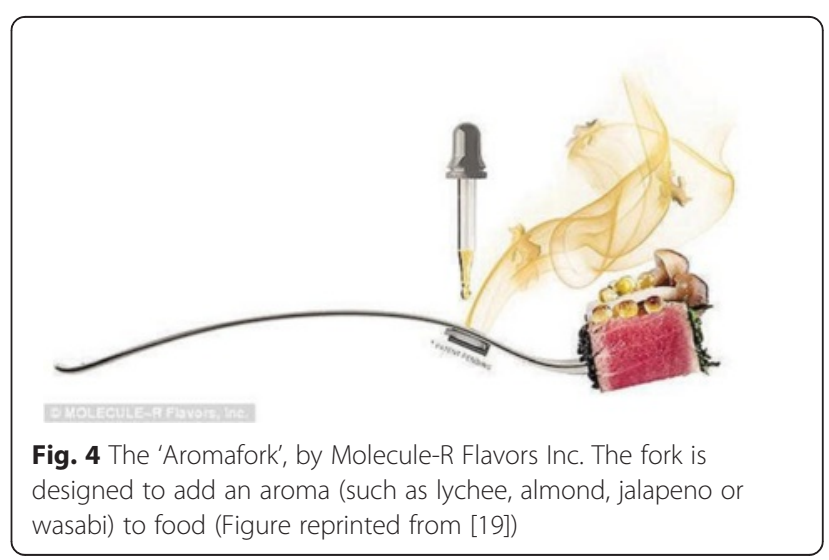




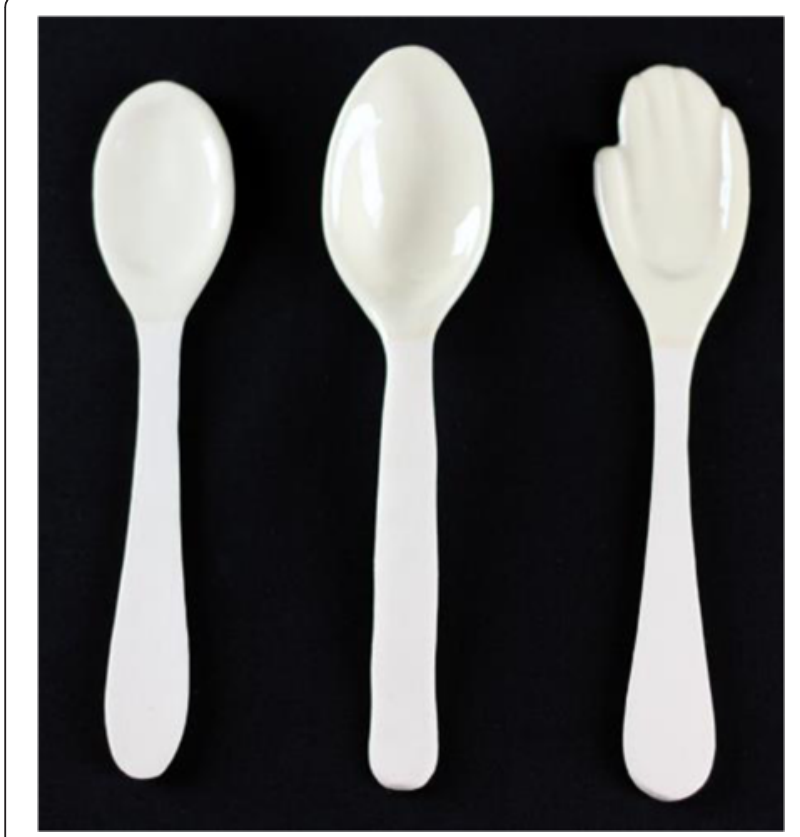

Fig. 5 Set of porous-handled ceramic spoons designed by Elizabeth Willing. Once again, the idea here is that essences can be added to enhance the dining experience; the suggestion being that diner guests could then experience a bowl of vanilla ice-cream with each of the three spoons [Source: Reproduced by permission of Elizabeth Willing]

perhaps give a nod to the shrimp skewered on a vanilla pod from star-chef Achatz at Alinea. This can also be considered as constituting a kind of organic cutlery (see [20]; though, it is worth remembering here that one really needs to crush or rear the vanilla pod in order to really release the most powerful aroma hit [21]), as can the stick of cinnamon bark that would greet the diner at the end of the meal-the latter fragrant utensil used to deliver a tempura of caramel with Meyer lemon and cinnamon sugar. Note also how in all of these latter cases, the use of real herbs and spices to deliver the desired aroma to the diner's nostrils obviously also helps

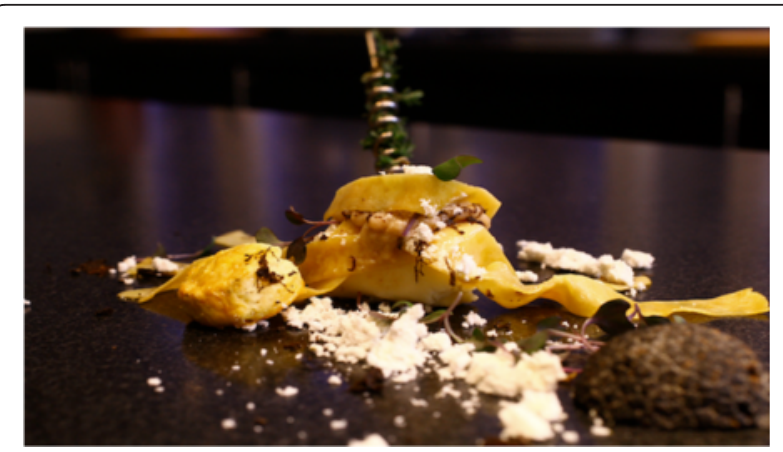

Fig. 6 Aromatic cutlery served at Homaro Cantu's Moto. (Source [14]) promote the authenticity of the smell through the eyes of the diner (see below).

Meanwhile, the chef-in-residence here at the Crossmodal Research Laboratory in Oxford, Charles Michel, has been known to serve his signature 'Kandinsky on a plate' dish on a painting canvas [22]. Naturally enough, therefore, he sometimes gives his diners a wide-bodied paintbrush to tackle the dish with (after giving the brushes a good wash, of course). On occasion, the chef would scent the bristles with truffle, or basil, oil. In this way, a very textured and aromatic impression can be delivered with each and every mouthful-a most memorable multisensory tasting experience, to be sure. ${ }^{9}$ Crucially, the aroma tends to get stuck in the bristles near where they are attached to the brush handle and hence an orthonasal olfactory input can be provided to the diner's nostrils mouthful after mouthful.

\section{Interim summary}

In this section, we have seen a diverse range of examples of aromatic plateware and aromatic cutlery. Clearly, a number of chefs, culinary artists, and designers have risen to the challenge of adding an additional olfactory element to the food that they choose to serve in the restaurant and experiential dining context. Some of the design solutions in this space also convey visually a certain visual appeal, and may convey notions of authenticity, think the vanilla pod or sprig of herbs mentioned above.

One other design solution that should be mentioned here, that achieves the same result though does not quite qualify as cutlery, comes from those culinary artists who spray aromatic scents on people's wrist before giving their audience/diners something to eat. One intriguing example of this approach comes from Caroline Hobkinson (see http://www.stirringwithknives.com/). She encourages people to eat a strawberry with their hands after having sprayed their wrist with the scent of black pepper. Meanwhile, we have heard of others (linked with Johnnie Walker Red Label) who in 2015 have been offering scented moustache wax for their more hirsute guests (e.g., at Huckle the Barber in East London) to enhance the taste of whisky (e.g., see http://www.dailymail.co.uk/ femail/food/article-3152363/Johnnie-Walker-experts-createworld-s-whisky-moustache-wax-enhances-flavour-drink.html). In the next section, we are going to take a closer look at one of the other popular routes to delivering an extra aromatic hit at the dining table, namely the atomizer and dry ice.

\section{Atomizers}

Augmenting the olfactory component of dining by means of an atomizer provides a cheap yet effective means of delivering an additional olfactory hit to diners. One of the first to suggest such an approach was the Italian Futurist F. T. Marinetti back in the 1930s. His 
recommendation was that meals should be eaten "to the accompaniment of perfumes . . to be sprayed over the diners" $[23,24] .{ }^{10}$ Diners nowadays would likely protest though should their waiter suddenly start spraying them with perfume during the course of a meal. However, using an atomizer to spray the scent of lavender over the food, specifically an oyster dish was certainly one of your first author's earliest memories of dining at The Fat Duck restaurant in Bray nearly a decade ago [25] (that said, though, your author does not remember any explicit link being made back to the Futurists). ${ }^{11}$

One other example worth mentioning here comes from the chilled citrus soup that was served at chef Cantu's Moto restaurant in Chicago (before the chef's untimely death [26]), the dish being finished off at the table with a little togarashi mist being sprayed over the bowl. 'This is my favorite part of the meal' said Cantu, 'I get to pepperspray our guests' [27]. Meanwhile, chef Youssef also utilized an atomizer to deliver the scent of saffron (Saffronel) over the Miso veloute with poached langoustine, tofu and corn dish at his Synaesthesia dining concept in 2015 (see https://kitchen-theory.com/). In this case, the use of the atomizer helped to deliver the same olfactory hit as using actual saffron in the dish, but at a fraction of the cost of the real thing (bear in mind here that saffron is, weightfor-weight, currently more expensive than gold; [28]). Meanwhile, for the Kaiseki menu in 2014, chef Youssef created a matcha tea aroma 'cloud' which was served in a goblet containing a sake, aloe vera and tapioca cocktail. A number of culinary artists have also been exploring the use of atomizers to add fragrance to a dish [29].

\section{Dry ice diffusion}

One particularly impressive example of the use of aroma poured over dry ice to create a fragrant smoky mist comes from Grant Achatz. The diner is presented with a cauldron filled with seaweed bubbling and smoking from the dry ice; when the waiter opens up the caldron in front of the expectant diner, the latter is greeted by the sight of a scallop sitting inside its shell placed atop seaweed. More importantly, though, a wave of citrusscented aroma rises up to fill the diner's nostrils. This is, once again, both a visually dramatic and olfactorily effective means of releasing fragrance to accompany a dish. The Fat Duck amongst many other restaurants has also used this approach. Blumenthal uses dry ice diffusion very effectively with the Jelly of Quail with Marron Cream and Oak Moss dish (see Fig. 7). As one commentator describes the dish during its recent appearance in Australia: 'This is one of the most visually exciting dishes: You have scented dry ice billowing from below a serving tray that looks like a patch of grass. You are getting the smell of the forest, the earthiness of the truffle and the taste of moss before you even get near eating

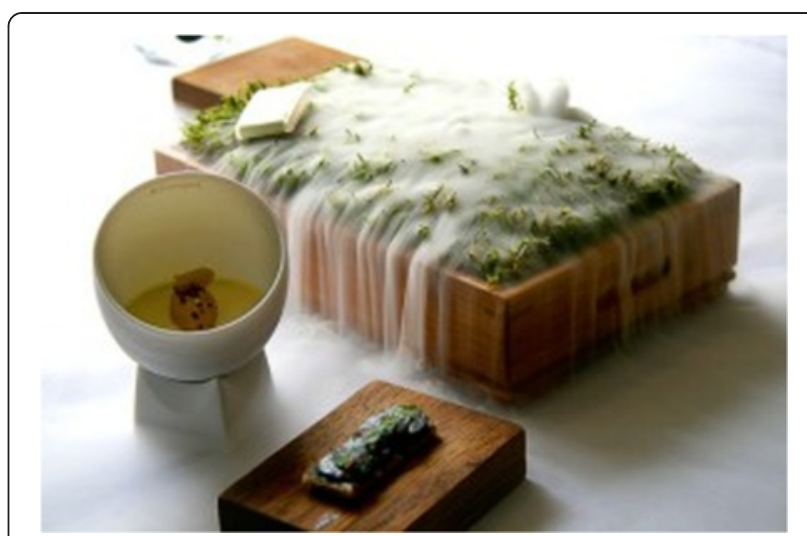

Fig. 7 The Jelly of Quail with Marron Cream and Oak Moss dish served at The Fat Duck [Image from https://salonlaurel.files. wordpress.com/2010/05/wk-ap044_fat_du_g_20090312164550.jpg]

the birds and fish that live here.' [30]. For the Nattura menu served in 2014, chef Jozef Youssef used dimethyl sulphide and dry ice diffusion to recreate the aroma of sea air, while serving with a marinated crayfish, seaweed and green bean amuse bouche. Here, one can also think of the layering of aromas-so there may be an ambient background aroma to a dish and then the foreground orthonasal aroma closely followed by the retronasal flavour of the dish itself. There are also, of course, some great smells that one simply would not want to eat. As chef Grant Achatz of Alinea fame puts it 'We've done firewood ashes, we've done leather, we've done grass, ... There's a lot of smells that you can't necessarily consume. You're not going to go out and chew on a baseball glove. But, in a lot of ways, a lot of smells that aren't necessarily edible smell good, and they remind you of certain aspects of food. So making those associations with what smells good or smells a certain way and pairing that with actual edible ingredients is one avenue that we take creatively.' (quoted in [17]).

Another device that is used by a number of chefs and molecular mixologists to create a dry ice vapour flavoured with any ingredient that happens to be inserted into the device is the 'cloud pour' (see http://www.chillistick.com/cloudpour.html). Chef Youssef often uses the cloud pour. So for example, in his most recent menu, Mexico, one of the dishes Memories of Oaxaca, consists of an Epazote (Mexican herb) cloud poured onto a hominy corn and shellfish soup. In an earlier concept Kai$s e k i$, a wheatgrass cloud was poured over a sake, aloe Vera and tapioca cocktail. The Hind's Head gastropub in Bray also sometimes uses the cloud pour as a safe means of working with liquid nitrogen (see https://www.facebook.com/hindsheadbray/posts/367265300060086; http:// www.chillistick.com/news/michelin-restaurant-loves-ourcloud-pour.html). Meanwhile, for those flying out of Heathrow's Terminal 2, 'Cloud Pourer' cocktails are also 
available at Blumenthal's The Perfectionists' Café (see http://www.hot-dinners.com/Gastroblog/Test-drive/hestonat-heathrow-we-test-drive-the-perfectionist-s-cafe).

The rotary evaporator (https://en.wikipedia.org/wiki/ Rotary_evaporator) also deserves a mention here. This is a device that provides a useful means for many kitchens to extract natural aromas from almost any substance. It was, for instance, used to great effect in the dark chocolate dessert served by chef Jordi Roca. Distilled coco bean essence created by use of the rotary evaporator enabled the chef to create a completely white sorbet that nevertheless still delivered a rich dark chocolate aroma to those lucky enough to try the dish [31].

\section{Interim summary}

The delivery of fragrance via an atomizer, liquid nitrogen or dry ice is not uncommon nowadays, at least not in a certain kind of modernist restaurant. Such approaches not only help to add an element of theatre/surprise to a dish, they can also be used to ramp up the olfactory hit delivered by a dish, oftentimes using a fragrance that may be different to, but hopefully complement, the dish itself. Of course, here one might be tempted to ask why bother? Why not simply apply the aromatic component to the food itself? Well, on the one hand, the atomizer/liquid nitrogen diffusion route can be used to deliver a wonderful orthonasal hit, while avoiding any unpleasant flavour (i.e. taste and/or retronasal smell) that can be associated with certain foods/flavours. Here, just think of vanilla which smells great, but tastes horribly bitter if you bite into a pod. It can also be used to deliver the aroma of other culinary elements that may be prohibitively expensive in their own right (think saffron or truffle). Perhaps more interesting, though, the addition of an extra olfactory element to a dish can also be used to help add an element of theatre to the proceedings (something that a growing number of chefs are increasingly interested in dishing up).

What is also interesting are those occasions when the chef augments the inherent aroma/flavour of the dish in order to try and create some sort of olfactory figure/ ground segregation [32]. One example of such an approach comes from the 'Messi's Goal' dessert that was served at El Celler de Can Roca in Spain [33]. This dish, a tribute to the famous football player from Barcelona FC, would arrive at the table as half a football covered with artificial grass that has been perfumed with the smell of freshly cut grass. While the smell of freshly cut grass undoubtedly creates an appropriate olfactory backdrop for the dish, there are likely few diners who would want to eat the stuff. It is, then the use of olfaction as scene-setting, or background to the flavours of the dish itself, which hopefully sit foregrounded centre stage in a diner's consciousness. ${ }^{12}$ Of course, those chefs who deliver a single-sitting tasting menu can fragrance the entire dining room. One such chef who has uses this approach is Paul Pairet in Ultraviolet in Shanghai [32].

At the opening of the Synaesthesia pop-up, the Marinetti Cubist Vegetable Patch dish (sesame and coffee marinated paneer cubes, mushroom crisps, pearl barley, crispy bacon, maple cream) was served with three pots of scented water which correlated with the ingredients in the dish. The guests were instructed to drop dry ice pellets into each pot to release the scent and, in turn, heighten the flavour of that particular element (or flavour; tarragon, pomegranate and then smoked bacon) in the dish. Meanwhile, one of Heston Blumenthal's dishes that is in some way similar (and that apparently works on around $85 \%$ of people) is his two-flavoured cinnamon/vanilla ice cream (see Fig. 8). Just imagine two squeezy bottles, one with cinnamon sticks the other with vanilla pods. Sniff one bottle for a few seconds and the brain adapts to that aroma. Hence, when you take a taste of the ice cream it should taste more strongly of the other flavour. If you repeat the procedure but this time sniffing the other bottle then the flavour of the ice cream switches. This is an entertaining use of orthonasal olfaction to change the perceived flavour of a dish. It can be argued that such dishes help illustrate how something unique can be brought to a dish by separating and playing with the olfactory elements. In the next section, we will take a closer look at the potential use of technology to deliver an added olfactory element to a dish.

\section{Augmented (digital) smell}

Some researchers, especially those in the humancomputer interaction community working out of the Far East have been investigating various ways in which to digitally deliver an additional olfactory element to food experiences (see http://digital-olfaction.com/). So, for

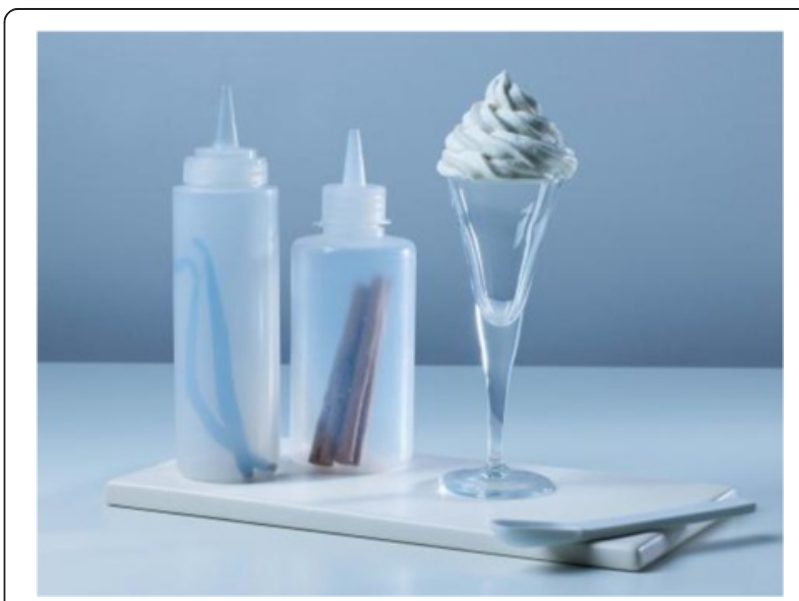

Fig. 8 Two-flavoured (cinnamon and vanilla) ice cream by Heston Blumenthal [Image from http://sageappliancesclub.co.uk/article/ cinnamon-and-vanilla-ice-cream] 
example, Narumi and colleagues [34] developed one such prototype multisensory display that, at least according to the developers, could help to change the perceived flavour of food by means of visual and olfactory AR. AR is defined as an experience of a physical, real-world environment whose elements have been augmented, or supplemented, by computer-generated sensory input. In Narumi et al.'s case, the idea was that the device recognizes the digital tag (e.g. a metacookie placed on top of the food) and then changes the visual appearance of the food accordingly. At the same time, the appropriate aroma for the food that the user can see via the headset is also released to enhance the 'realism' of the situation (see Fig. 9). However, a quick look at the headset probably tells you all you need to know about how soon you will be seeing such technology in the restaurant setting. Other scent-enabling technologies look more promising though (see https://www.prote.in/en/feed/ 2014/04/sensabubble).

In the future, it would also seem likely that there may be a role for the hand-held technologies that one finds in most people's pockets in augmenting the dining experience too. Indeed, the last few years have seen something of an explosion of interest in digital plug-ins (e.g. the Scentee; https://scentee.com/). ${ }^{13}$ Certain of these can already release specific food aromas; just take the following: "Available scents include rose, mint, curry, jasmine, cinnamon roll, lavender, apple, strawberry, ylang-ylang (a fragrant flower), coconut, and if you remember the fried corn soup fritters at KFC Japan from earlier this year, the corn soup scent should come as no surprise. There's also a limited-edition Korean BBQ collection with two meat scents and baked potato. Other scents are also in

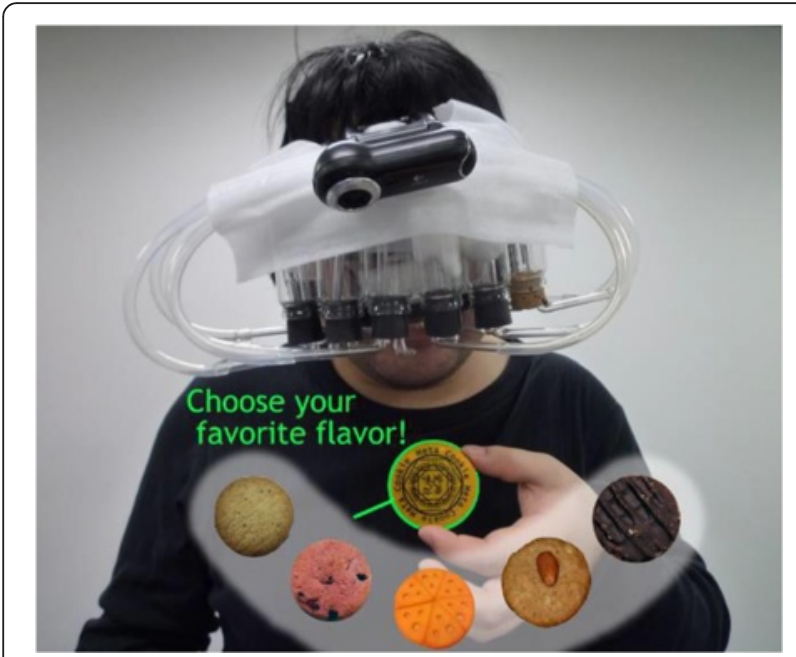

Fig. $9 \mathrm{Hmmmmm}$, tasty! Sometimes $\mathrm{HCl}$ researchers perhaps spend a little too much time thinking about what is possible with technology and not enough time thinking about what is actually likely to be applicable [Figure showing AR multisensory flavour display; reprinted from [34], with permission] the works." [35]. Currently the bubble-shaped Scentee (see Fig. 10) retails at around $\$ 5$ in The USA and can deliver around 100 bursts of a fragrance. ${ }^{14}$ There are, though, a couple of potential limitations that will likely limit the uptake of this kind of technology at the dining table, on the one hand, most commercial devices can only release a single scent, obviously not ideal for a multicourse-tasting meal. Furthermore, it can be difficult to simulate a suitably realistic aroma in certain cases.

\section{Interim summary}

Despite the media's excitement, the various digital olfaction solutions that have been launched thus far all have more the feel of proof-of-principle prototype (Narumi et al.) [34], or 'marketing gimmick' [36] than genuine gastronomic intervention or godsend. Certainly, there has been little evidence of such technology being incorporated into the serviceware of high-end restaurants yet $[20,37]$. If such wearable devices could be made more, well, wearable-think wireless and light-weight, not to mention capable of delivering a variety of aromas-then who knows, perhaps they might make an appearance at some restaurant one day. However, the current need to make sure that there is some sort of QR code, or tag (i.e. metacookie), on the food itself, obviously limits the mainstream utility of the AR technology, impressive though it undoubtedly is.

\section{Smell-enhancing attire}

One other solution, that has both a more traditional (albeit niche) and a more modern incarnation is the

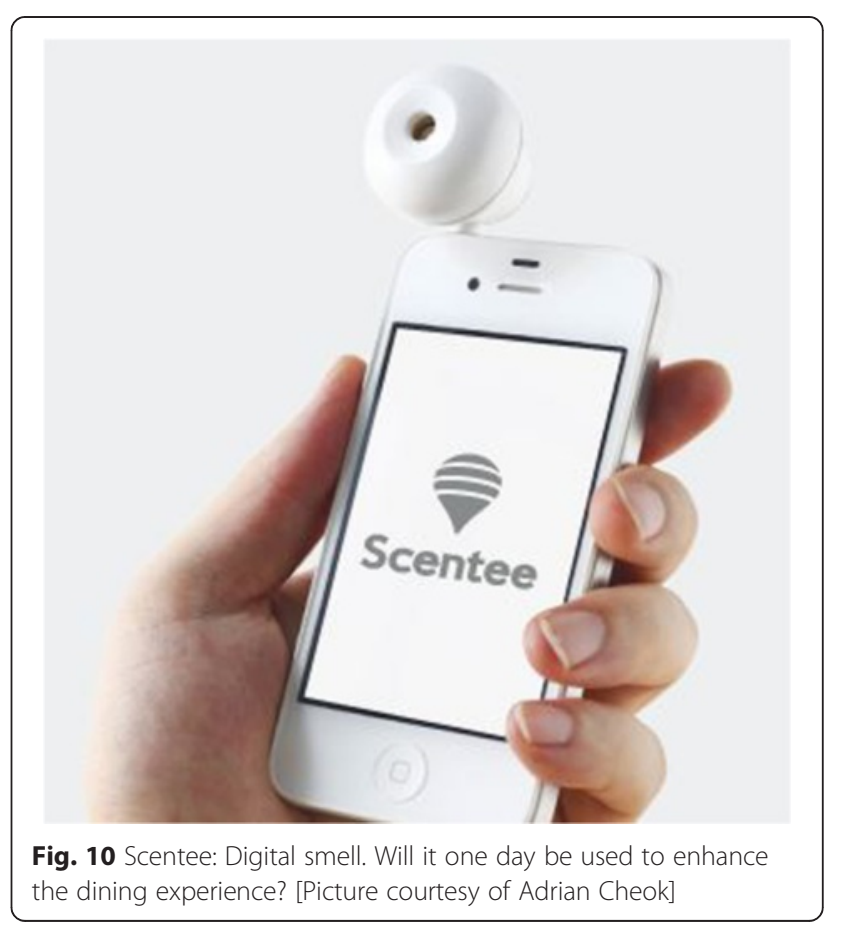


attire, or hat, that the diner might wear in order to enhance the olfactory component of dining. The niche version relates to the way that some French diners would traditionally have eaten ortolan, a rare bird of the bunting family with an apparently exquisite aroma [38]. The bird is eaten whole, and was purportedly on the menu for ex-president Francoise Mitterand's final banquet shared with 40 friends shortly before his death in 1996 (see Fig. 11). According to Baxter, these thumb-sized birds were: 'Kept alive until the last minute, they were drowned in Armagnac, plucked, sautéed, and served in individual lidded pots called cassolettes, which could only hold one or two birds. One ate them whole, including legs, bones, and intestines (although the more fastidious left the head). Their aroma was so delectable that, before opening the cassolette, diners draped napkins over their heads, conserving every whiff.' Notice how the napkin in this case serves to capture all of the aroma of the dish, while at the same time removing vision during the act of consumption. This will presumably have the effect of accentuating the diner's pleasure in their gastronomic experience. One might wonder whether removing vision is especially appropriate here in helping to hide the perhaps unpleasant sight of the whole bird. Notice, though, how the situation here is somewhat different from all those who dine in the dark restaurants where no information about what is being eaten is often provided, and where people rarely have anything good to say about the taste/flavour of the food [20].

In a related vein, but in some ways less extreme, the final year project of one of the students at an art/

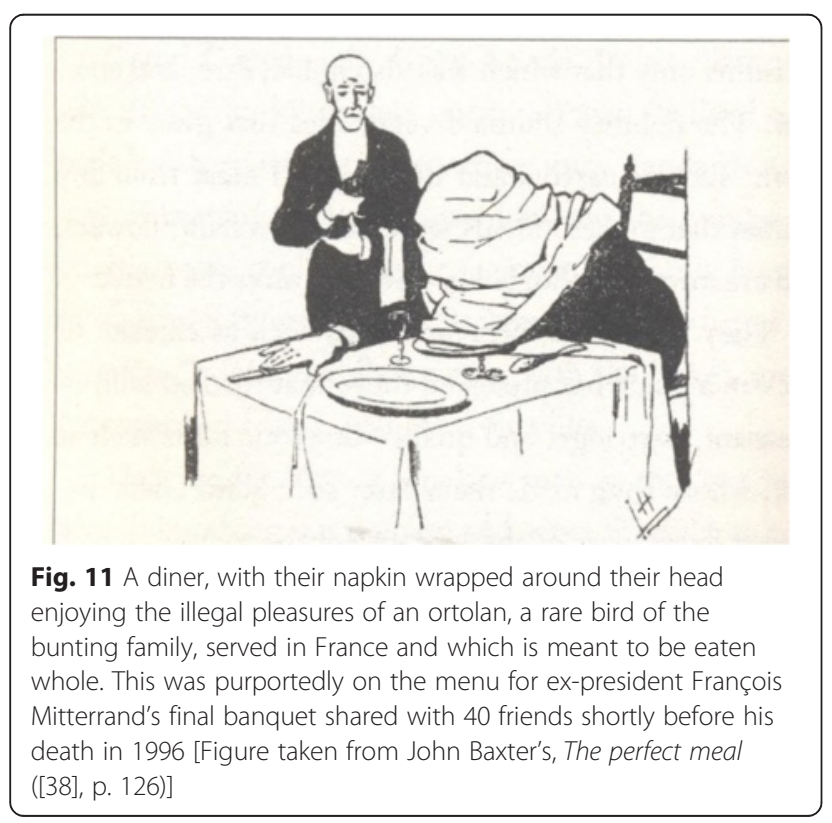

fashion college recently involved the creation of a range of smell-capturing hats and caps for diners. Less extreme than the napkin example above, these future fashion items still allowed the diner to see their food while at the same time helping to funnel the aromas emanating from the dish towards the diner's nostrils. This kind of approach to enhancing the dining experience is reminiscent of the headspace capture techniques that have been used for years, by companies such as Givaudan in order to capture the flavours of unusual foods (e.g. [39]; see also [40]). A potentially much cheaper and more widely available attire solution here might come from the nasal dilator.

\section{Nasal dilator as flavour enhancement device?}

One less glamorous, but potentially no less effective, means of enhancing a diner's olfactory enjoyment of a meal would seem to be to use The Breathe Right nasal dilator, first marketed back in 1993 (as the Breathe Right $^{\text {tm }}$ Nasal Strip; CNS Inc., Chanhassen, MN). These off-the-shelf strips were originally introduced for use by sportsmen and women; the idea being to place the strip on the bridge of the nose just above the fleshy portion of the nostrils. The nasal dilator is supposed to exert a spring-like action preventing the sides of the nasal vestibule from collapsing inward during nasal inhalation. Scientific tests have revealed that resistance in the nasal airways is reduced by as much as $30 \%$ or more when wearing one of these devices [41]. Meanwhile, nasal imaging reveals a $25 \%$ increase in airspace volume in the soft anterior region of the nasal passage and an $11 \%$ increase in the bony posterior region [42]. In the context of the present article, then, one might wonder whether the nasal dilator could be used to enhance the dining experience, if olfaction is, as we are led to believe, such a large part of the dining experience.

Over the years, a number of studies have provided results relevant to addressing this question. For instance, Hornung et al. ([43]; see also [42]) reported that wearing one of these strips led to olfactory stimuli being rated as significantly more intense (by $16.7 \%)$ than was the case for those participants who were not wearing one. Furthermore, those wearing such a device also show significantly enhanced odour identification abilities (99 vs. 78 \% correct identification, respectively, at least according to the results of one test; [42]); those wearing a dilating strip were also able to detect odours at a significantly lower concentration than those who were not. ${ }^{15}$

That said, the story appears to change somewhat when it comes to people's evaluation of actual foods. In one of the only studies of its kind, Raudenbush and Meyer [44] assessed the effects of wearing a nasal 
dilator on people's ratings of the pleasantness, intensity, and their sampling behaviours towards ten foods (that included chocolate icing, butterscotch pudding, applesauce, peanut butter etc.) that the participants $(N=88)$ were encouraged to sample with a spoon. In this between-participants study, participants wearing a nasal dilator did indeed rate the foods as more intense (1.59 points higher on an 11-point scale). That said, they also rated them as tasting less pleasant (an 0.7 point difference on an 11-point scale in this case), than did those participants who were wearing a placebo strip instead. What is even more striking, those wearing the nasal dilator consumed $61 \%$ less food. ${ }^{16}$ In this case, intensity was correlated with pleasantness and consumption, i.e. as intensity increased, both pleasantness and consumption declined.

As yet, then, there does not appear to be any clear evidence in support of nasal dilators being utilized as an aid to enhancing the dining experience. There is, though, perhaps a question here about the use of commercial foods here. One can easily imagine how the taste qualities of such products would presumably already have been optimized for liking. Who knows, then, whether the results of Raudenbush and Mayer's [44] study would have been any different had foods with a less intense aroma had been used instead? One other thing to bear in mind here was that all of the foods were removed from the fridge $30 \mathrm{~min}$ before serving. Obviously, a hot dish might well be expected to deliver more of an orthonasal olfactory hit, and hence benefit more from the nasal strip. Given the potential importance of the nasal strip as a potentially cheap and simple means of enhancing the olfactory contribution to our anticipation and enjoyment of the flavour of food, more research is still needed in order to confirm just how generalizable these nasal dilator findings really are. It would be a shame to miss a trick with such a seemingly simple solution here. $^{17}$

A final example that is worth dwelling on for a moment here is the device that was patented back in 1996 by Knight that was designed to enhance to the olfactory experience of those suffering from some sort of olfactory deficit. According to Avery Gilbert ([8], p. 83), it resembled: 'a double-ended turkey baster with the bulb in the middle equipped with one-way valves. The user positions one end of the device over, say, a bowl with chili, then squeezes and releases the bulb, and it fills with air. Now the user inserts the other end in his nostril and squeezes again, forcing a bulb full of chili-scented air up his nose.' While this device was originally designed to help those with limited olfaction, one could perhaps imagine how some culinary artist or experience designer might think about utilizing such a device in order to give diners' an enhanced olfactory hit of some delicious aromatic dish or another. It is, though, only a relatively small step from capturing the aroma of a dish with such a device through to the notion of eliminating the actual food itself, as we will see in the next section.

\section{Interim summary}

In this section, we have seen a number of examples of scent-enhancing attire and scent-capturing tools. Such solutions are currently more the domain of the arts student and of disability aids than high-end cuisine. Who knows whether we will see any of these solutions appearing in the restaurant one day soon. One important theoretical issue to bear in mind here, though, relates to the phenomenon of perceptual constancy. Perceptual constancy refers to the tendency that we have to perceive familiar objects and stimuli as having standard appearance (e.g. size, shape, colour or loudness) regardless of any changes in the sensory input. The result is that we tend to perceive objects/ stimuli as it is, or as it is assumed to be, rather than reconstructing an impression that accurately reflects the actual sensory input [45].

Importantly, perceptual constancy operates in the olfaction just as it does in the other senses. In one study, for example, Teghtsoonian and Berglund [46] had their participants sniff at one of two flow rates, one twice as great as the other. The participants then had to make magnitude estimation judgments concerning a variety of suprathreshold olfactory stimuli. Interestingly, and perhaps counterintuitively, the dramatic variation in the subject-controlled flow rate exerted no influence whatsoever on the perceived strength of the odorants. This null result was taken to suggest some kind of size constancy mechanism, or invariance, operating in olfaction, with judgments of odour intensity being made in relation to perceived vigour of sniffing. Teghtsoonian et al. ([46], p. 151) went on to conclude that: 'It may be argued...that, even if flow rate is an important parameter of the proximal stimulus for odour strength (discharge rate in the olfactory nerve), information about sniff vigour may control its effect on the perceptual response.' That said, Le Magnen [47] found that threshold for the detection of eucalyptol odour was lower in those with higher inhalation rate (see also Rehn [48] for similar results). The reason why it is important to consider the existence of perceptual constancy in the olfactory modality is that it might, just possibly, minimize the effectiveness of the nasal strips, and other olfactory-enhancing attire we have come across in this section. While more research is undoubtedly needed on the topic, the suggestion that emerges from studies of this phenomenon in the other senses is that it should have less influence on perception for those stimuli that are less familiar to us-think unusual flavours, rather than the widely- 
available commercial food products used by Raudenbush and Meyer [44].

\section{The olfactory dinner party: who needs to eat the food anyway?}

Thus far, all of the examples we have seen have involved enhancing the olfactory component of a meal, but, in all cases, food still formed part of the dish. Some chefs and culinary artists have, though, been tempted to go even further. After all, if scent really is $95 \%$ of flavour (as some would have us believe; this at the upper end of the range of percentages one finds in the literature; see [4] for a review), then one might wonder why not just cut the other $5 \%$, simply deliver the aroma of the food and reduce the calorie count into the deal. ${ }^{18}$ Interestingly enough, people have been thinking about the notion of the pure olfactory dish, or meal, for many years now. Some of the first suggestions along these lines appeared back in 1930, and, once again, we have the Italian Futurist to thank for making the suggestion. Just take the following:

In fact, in the ideal Futuristic meal, served dishes will be passed beneath the nose of the diner in order to excite his curiosity or to provide a suitable contrast, and such supplementary courses will not be eaten at all. ([49], p. 43).

One also finds Evelyn Waugh in print in the same year speculating about something seemingly quite similar in his novel Vile Bodies [50]:

He lay back for a little in his bed thinking about the smells of food, of the greasy horror of fried fish and the deeply moving smell that came from it; of the intoxicating breath of bakeries and the dullness of buns... He planned dinners, of enchanting aromatic foods that should be carried under the nose, snuffed and then thrown to the dogs... endless dinners, in which one could alternate flavour with flavour from sunset to dawn without satiety, while one breathed great draughts of the bouquet of old brandy.

The last few years have seen something of a resurgence of interest in the Futurists and their crazy, wonderfully-inventive ideas (e.g. see [51, 52]). As such, there have been a number of dining events where the idea of the purely olfactory dining experience (or at least the purely olfactory course) has been recreated (e.g. see Fig. 12 for one such representative example [53]). In fact, given the nature of some of the Futurist's recipes, sniffing the dishes might well have been preferable to eating them anyway [51].

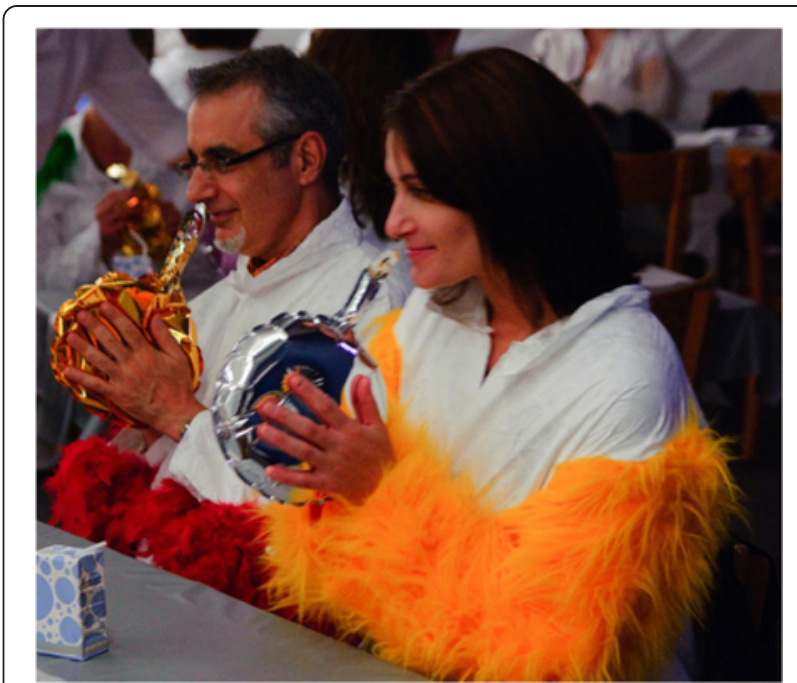

Fig. 12 'Aerofood'. A mylar balloon holding food scent, one of the dishes served at The Tactile Dining Car, a participatory dining and performance installation held at the Flashpoint Gallery, Washington DC, 9-24 September 2011. Source: Reproduced with permission of banished? productions/Carmen C. Wong (and found in [50])

The idea of inhalable food has certainly become a lot more practicable in recent years with the development of machines, and now commercialized devices, designed to deliver vaporised food. For instance, American scientist David Edwards and French culinary designer Marc Bretillot invented a gadget that they christened 'Le Whaf'. This clever little device transforms food into a cloud of flavour. First, the food, say a lemon tart, is boiled down into liquid form. Next, the resulting mixture is strained and transferred to a carafe. Then, ultrasound is used in order to transform the liquid into vapour. Finally, one simply pours a cloud of lemon tart into a glass and sips it with a straw (see the company's website http:// www.aerodesigns.com/ for a number of other instantiations of this concept).

The sorts of creations that the chef might come up with if using such a device were highlighted at the launch party of Le Whaf in 2012. Massimo Bottura, from the Osteria Francescana (in Modena, Italy), prepared a canard' à l'orange; Ben Shewry from Attica (in Melbourne, Australia) mixed four clouds from rice, rice vinegar, soy sauce and ginger to create a surprising gaseous concoction. Meanwhile, chef Homaro Cantu from Moto (in Chicago, USA) used some of the miracle berries of which he was so fond, together with a handful of other ingredients including a mixture of hazelnut liquor and lemon vodka, in order to deliver what was supposed to be the first breathable chocolate cake. Bottura has taken the idea back to his restaurant in dishes such as his Parmigiano Reggiano in textures with Parmigiano 


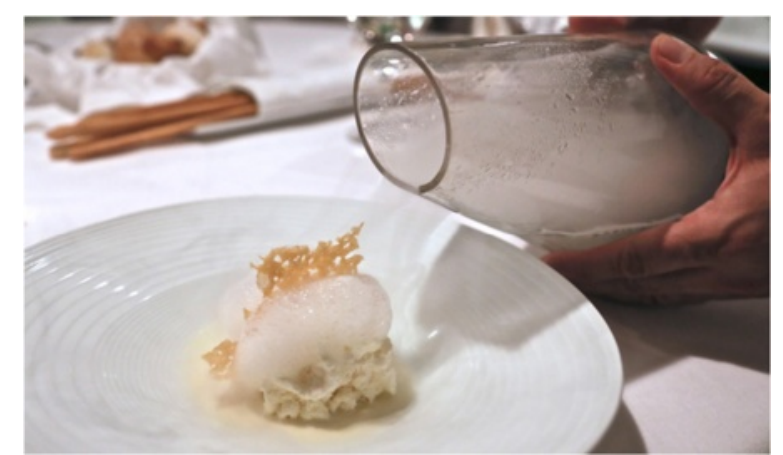

Fig. 13 Parmigiano Reggiano in textures with Parmigiano cloud as served by Massimo Bottura at the Osteria Francescana in Modena, Italy (Figure taken from [54])

cloud (see Fig. 13, [54]). Here, it is worth noting that a number of culinary artists have started to work with edible inhalable/flavours as well (e.g. http://www.aliceandthemagician.com/blog/). One can deliver inhalable cocktails or drinks using the Vaportini (see http:// www.vaportini.com/history.html). And taking things to a much larger scale, the notion of inhalable flavours has recently been extended to a room-filling scale with the olfactory, or breathable, Alcohol Architecture bar recently opened at Borough Market, London by the fabulous Bompas \& Parr in London (http:// concreteplay ground.com/auckland/food-drink/drink/ this-pop-up-bar-of-dreams-specialises-in-breathable-booze/; http://bompasandparr.com/projects/view/alcoholic-architecture1/).

What all of these inhalable ideas lack, though, and what is presumably crucial, is the oral-somatosensory element of stimulation while enjoying food. And, while the inhalable dish or drink has a certain appeal, our gut feeling is that most diners are going to feel a little shortchanged if they were only given an inhalable meal!! Inhalable drinks seem, if anything, like a more plausible route to take here, given that we do not always drink for nutrition and sustenance. Consistent with this notion, there has been a recent growth of breathable cocktails (e.g. http://cassandradaily.com/life/raising-the-bar/). Our bet, though, is that inhalable aromas and mists will work best when delivered as a mist over a dish, or in a glass on the side to accompany it-i.e. enhancing the consumption experience rather than replacing it.

\section{On the authenticity of flavours}

Finally, in this article, it is important to raise one potential concern about all of these attempts to augment the olfactory component of a dish, be it through aromatic plateware/cutlery or via atomizer or scent-enabled plugin, Namely, 'authenticity'. Now, assuming that this augmenting of the orthonasal olfactory component of flavour perception really works (as in, it is appreciated by diners), it does raise the questions of the 'authenticity' of flavour. The worry here is that perhaps although our food experiences can be enhanced in this way, might the diner not in some way feel tricked? This kind of idea inadvertently presents itself as Jonathan Coutu, whose firm created the olfactorily enhanced eating utensil, suggests in one interview that: 'The initial idea was to reinvent the traditional fork into an improved utensil that would trick people's mind by liberating an intense flow of aromas.' (quoted in [19]), or take the text on the Aromafork website itself: 'Trick your mind with aroma $R$ Evolution' [19].

Of course, similar concerns about the artificial manipulation of aroma emerge in other places too. Just take the example of adulterating one's spirits or wines to give them the appearance of something much more interesting/expensive (e.g. see the Whiskey Element for one such example, [55]). Here, one is also reminded of the suggestion by Hervé This of a few years ago: 'to add the aromatic molecule, vanillin, to a cheaper whiskey before serving it to guests because vanilla is found in some more expensive whiskeys.' [56]. ${ }^{19}$ Issues of authenticity soon crops up when considering This's enthusiasticallyexpressed ideas around what he has christened 'note-bynote cuisine' (see [56-58]). Now, assuming for a moment that the flavour experiences so-created are pleasant, ${ }^{20}$ one is still left worrying about the authenticity of it all, and how much that matters to the diner. According to This, note-by-note cuisine would allow us to recreate a classic bottle of wine. But is that really what the wine expert is paying all that money for? We think not, at least not always. Perhaps what the diner, or for that matter drinker, is really after is an 'authentic' experience, rather than necessarily caring all that much about the actual taste/flavour itself [59].

In the best-case scenario, perhaps it turns out like the placebo effect. That is, even though you know that you are using a placebo, it can still work, at least to a certain degree, and under certain conditions [60]. Maybe here the key thing distinguishing the augmenting of the olfactory element of a dish in the modernist restaurant case and that described in the adulterated whiskey (or should/could that read whisky?) case is the fact that the theatricality of the performance in the restaurant draws the diner's attention to the fact that everything is not as it seems as far as the aroma is concerned. By contrast, the implication in the spirits case is that the information would (or, at least, might) be hidden/disguised in some way. As long as the diner/consumer is aware of what is happening, they can make up their own mind about whether they like it, whether it was worth the price.

On the other hand, of course, one might simply ask whether all of our flavour experiences are, in some 
sense, fake. As Khatchadourian [61] put it in an article for The New Yorker magazine: 'The consumption of food flavorings is one of the modern era's most profound collective acts of submission to illusion.' Thus, the conclusion here is that it is currently a little hard to predict how exactly the diner/consumer will respond to the kinds of olfactory enhancement of flavour that have been outlined here. Perhaps, it is part of the role of the modernist chef and culinary artist to play in the space and figure out what works well, and more importantly, what people are willing to pay for in terms of augmented eating experiences. In recent years, the work of a number of designers and culinary artists can certainly be seen as playing in exactly this space (see [20] for a number of examples).

\section{Conclusions}

While assigning a precise value to the role of any one of our senses in the enjoyment of eating and drinking is a tricky business (see [4] for a review), the majority of scientists would now seem to agree broadly with the claim that the majority of what is colloquially called taste (though should more properly be called flavour) actually comes from the nose. Certainly, a large part of our enjoyment of food and drink depends on the senses of orthonasal aroma and subsequently retronasal smell (in the flavour percept itself). Awareness of this fact is slowly spreading amongst the (modernist) chefs and culinary artists who are now starting to design their culinary creations a little differently, thinking, on the one hand, about how best to ensure that as much of the aroma of a dish reaches the noses of their diners as possible. In the process, we have seen how the addition of an extra olfactory element to mealtimes is often used to add an element of theatre to the experience as well. Sometimes it is used to induce particular emotions, trigger certain memories, or to induce certain nostalgia by presenting a smell that the diner may not have come across for a number of years [17].

So, finally, returning to the question that we posed at the start of this piece: What exactly is (are) the USP(s) of adding an extra olfactory element to a dish? Why not just ramp up the aroma as some restaurants are apparently doing ([15]; see also http://nordicfoodlab.org/blog/ 2012/03/capturing-aroma)? Well, a number of possible reasons that the chefs and culinary artists have come up with have been outlined here: (1) To add an element of theatre to the proceedings; (2) To deliver the same olfactory experience but at a lower cost; (3) To achieve figure-ground segregation between a scene-setting aroma, and the aroma of the dish itself; and (4) To deliver those aromas that are associated with flavours that just do not taste so good.
On the flip side, however, there are, of course, potential problems and limitations to be aware of. One danger is that this kind of sense-by-sense approach to delivering a truly multisensory dining experience just looks 'gimmicky' or forced. Those who think in this way would likely expect that such augmented olfaction, be it digital or otherwise, will never catch on in the mainstream. There is also the problem of the authenticity of the ensuing experience, and the phenomenon of perceptual constancy that may also limit the effectiveness of some of the solutions that have been suggested in this area too.

Looking forward, growing interest in the olfactory contributions to the dining experience is certainly not restricted just to the plate itself. There is also a growing awareness of, and interest in, the scent of, not to mention around, the restaurant [20,32]. Some restaurants, in fact, now explicitly ban their wait staff from wearing any scented products [62]. In other words, chefs, restaurateurs, culinary artists and other experience designers are increasingly wanting to take control of the olfactory landscape (or 'smellscape', as some have called it; [63, 64]) that surrounds (both spatially and temporally), their diner's (or for that matter drinker's) consumption experiences.

The focus in this article has been on high-end dining and culinary artistry (not to mention culinary artists; the last two sounding similar, but in fact actually being quite different). However, in the future, we believe that by far the biggest uptake of ideas in the space of olfactory dining will be in mass-market food and beverage packaging (e.g. see [65]). You only need to note here how much of what we eat and drink is actually consumed direct from packaging. However, important though this topic is, a full and decent coverage of the world of olfactorily enhanced food and beverage packaging lies firmly beyond the scope of the present article.

\section{Endnotes}

${ }^{1}$ At the outset, an important distinction to be drawn here is between orthonasal and retronasal olfaction [66, 67]. The former term is used to refer to the inhalation of external aromas, as when sniffing (just think of the Bisto Kid). By contrast, retronasal olfaction refers to the perception associated with the pulsing of air from the back of the nose (i.e. the posterior nares) whenever we swallow (e.g. [68]). Now, while there are undoubtedly perceptual similarities between these two kinds of olfactory experience [69-72], there are also a number of important differences as well [73]. What is more, only the latter, retronasal olfaction, constitutes part of ISO definition of flavour $[74,75]$. 
${ }^{2}$ As Smith [76] notes in The Oxford companion to American food E drink: "The grandest hotels were entertainment in themselves and had a near monopoly as sites for banquets and elegant dining...Dinners were choreographed with military precision. A gong summoned guests for dinners at which waiters in unison removed silver domes covering the various dishes creating a public spectacle akin to the most opulent dinners in private homes".

${ }^{3}$ And perhaps one could also frame the waiter in those restaurants where they shave a little truffle over your plate directly at the table as doing something similar. The aroma of these most expensive of ingredients saved for the nostrils of the expectant diner.

${ }^{4}$ Not drizzles, you note!! This to avoid the wrath of British chef Simon Hopkinson, who does not understand why restaurant menus have to 'drizzle' their balsamic. Does not pouring or splashing the vinegar sound just as appealing, he asks (see [77]).

${ }^{5}$ How often, after all, have you been served a dish in a plastic bag in a restaurant before?

${ }^{6}$ In the latter dish, one can imagine how the diners may be surprised by the sudden delivery of the aroma once they start to eat the dish.

${ }^{7}$ There is, though, perhaps a question here as to how many people out there would be willing to pay $£ 36$ for a set of 4 forks, a full set of 21 aromas, and 50 rounds of blotting paper. Bloor, by comparison, sells a pair of forks/spoons and a couple of small bottles of scent for around $£ 5$ a set.

${ }^{8}$ And in so doing, reminding the first author of a similar peculiar experience on an Asian airline not so long ago, when he was offered a metal fork and a plastic knife to eat his meal. As you can imagine, there was something just not quite right about the ensuing experience.

${ }^{9}$ Though, from what we have seen thus far, not everyone is quite ready to use such a repositioned bit of cutlery just yet.

${ }^{10}$ In her description of one of the Futurist dinners, David ([78], p. 61) wrote: "Meals were to be eaten to the accompaniment of perfumes... to be sprayed over the diners, who, fork in the right hand, would stroke meanwhile with the left some suitable substance - velvet, silk, or emery paper."

${ }^{11}$ This is "food as theatre" as Elizabeth Carter put it a few years ago [79].

${ }^{12}$ The ambient smell of freshly-cut grass was also used in the Singleton Sensorium event in order to help bring out the grassy notes in the whisky that people were tasting [80]. Fresh cut grass aroma also came out top in terms of the most evocative summertime smell in a recent survey [81].
${ }^{13}$ According to Harris [35]: 'Finding just the right smartphone notification for a text, email or alarm is a big decision. People that choose animal sounds should have their phones taken away. But what if you could make your phone smell like your favorite food every time you got a text?'

${ }^{14}$ Oscar Mayer (a Kraft-owned meat brand) released an iPhone attachment last year. While originally sold as a Bacon-scented alarm clock (see Wake Up \& Smell The Bacon-from the Oscar Mayer Institute For the Advancement of Bacon, OMIFAB; [36]), one could certainly imagine its use in enhancing the dining experience.

${ }^{15}$ These are presumably all benefits of getting more air into the nasal passages. Indeed, consistent with this view, sniff duration, sniff flow rate and sniff volume were all significantly higher in those wearing the dilator than in those who were not.

${ }^{16}$ Could this, then, be an effective aid to weight loss, one wonders?! Some people are clearly getting a little overexcited, as evidenced by the title of one article "Chewing and swallowing are so yesterday" [82].

${ }^{17}$ Though, then again, who wants to look like a 'jock' (https://en.wikipedia.org/wiki/Jock_(athlete)) while dining out at a fancy restaurant?

${ }^{18}$ And once one gets to the concept of purely smellable food, the link to perfume becomes one step closer. One popular concept in recent years has been to think about marrying perfumery with cuisine (e.g. see [83]; 'Stop and Smell Your Dinner'; http://artandolfaction.com/programs/stop-and-smell-your-dinner/). To give just one example here, a few years ago, the French three-Michelin-star chef Anne-Sophie Pic opened a restaurant in Paris, called Le Dame de Pic that features three menus, each one of which was aligned around a different scent: Vanilla, the sea and spices [84]. Meanwhile, in the world of molecular mixology, 2014 saw the opening of the Fragrances bar at the Ritz-Carlton, in Berlin (see http:/www.ritzcarlton.com/en/Properties/Berlin/Dining/Fragrances/

Default.htm). According to the website, 'Let us enchant you in our new bar with outstanding drinks based on exclusive fragrances and personal memories. Fragrances is the first bar dedicated to the art of cocktails in combination with the world of perfume and aromas. Hand-picked fragrances of renowned brands by Giorgio Armani, Yves Saint Laurent and Guerlain are the inspiration for the unique drinks created by bar manager Arnd Heissen. Follow your senses and escape from your everyday life at The Ritz-Carlton, Berlin. Indulge in an unique sensual experience with fragrance cocktails!'

${ }^{19}$ We certainly want to avoid the danger that one just ends up with something like Aldous Huxley's [85] 
'Chemical wine', which makes an appearance in his dystopian novel Brave New World.

${ }^{20}$ Something that your first author has yet to see in any of the public demonstrations that he has had the pleasure of attending (see also [56]).

\section{Competing interests}

The authors declare no competing interests.

\section{Authors' contributions}

CS \& JY wrote all parts of this review. Both authors read and approved the final manuscript.

\section{Acknowledgements}

CS would like to acknowledge the AHRC Rethinking the Senses grant (AH/ L007053/1). The authors confirm that informed written consent was received for publication of the manuscript and figures. Where appropriate (e.g. Fig. 2), written informed consent was also obtained from the diner shown for publication of their image in this manuscript. The consent forms are held by the authors and are available for review by the Editor-in-Chief.

\section{Author details}

${ }^{1}$ Crossmodal Research Laboratory, Department of Experimental Psychology, Oxford University, Oxford OX1 3UD, UK. ${ }^{2}$ Kitchen Theory, London, UK.

Received: 27 August 2015 Accepted: 2 November 2015

Published online: 14 November 2015

\section{References}

1. Brillat-Savarin JA. Physiologie du goût The philosopher in the kitchen/the physiology of taste]. J. P. Meline: Bruxelles, Translated by A Lalauze (1884), A handbook of gastronomy. London: Nimmo \& Bain; 1835.

2. Meggiato R: The science of food smells. Fine Dining Lovers. 2015:May $29^{\text {th }}$. Downloaded from https://www.finedininglovers.com/stories/food-sciencesmell/ on 24/07/2015.

3. Martin GN. A neuroanatomy of flavour. Petits Propos Culinaires. 2004; $76: 58-82$

4. Spence C: Just how much of what we taste derives from the sense of smell? Flavour. 2015.

5. Spence C, Smith B, Auvray M. Confusing tastes and flavours. In: Stokes D, Matthen M, Biggs S, editors. Perception and its modalities. Oxford: Oxford University Press; 2015. p. 247-74.

6. Piqueras-Fiszman B, Spence C. Sensory expectations based on productextrinsic food cues: An interdisciplinary review of the empirical evidence and theoretical accounts. Food Qual Prefer. 2015;40:165-79.

7. Barden D: Analyzing volatile organic chemicals in food: Emerging trends and recent examples. February $14^{\text {th }}, 2013$. Downloaded from http:// www.americanlaboratory.com/913-Technical-Articles/130837-AnalyzingVolatile-Organic-Chemicals-in-Food-Emerging-Trends-and-Recent-Examples/ on 19/08/2015.

8. Gilbert A. What the nose knows: the science of scent in everyday life. New York: Crown; 2008

9. Druaux C, Voilley A. Effect of food composition and microstructure on volatile flavour release. Trends Food Sci Technol. 1997;8:364-8.

10. Taylor AJ, Roozen JP. Volatile flavor release from foods during eating. Crit Rev Food Sci Nutrit. 1996;36:765-84.

11. Stevenson RJ. The psychology of flavour. Oxford: Oxford University Press; 2009.

12. Spence C, Okajima K, Cheok AD, Petit O, Michel C: Eating with our eyes: From visual hunger to digital satiation. Brain Cognit. 2015. doi:10.1016/ j.bandc.2015.08.006.

13. Michel C, Woods AT, Neuhäeuser M, Landgraf A, Spence C. Orienting the plate: online study assesses the importance of the orientation in the plating of food. Food Qual Prefer. 2015;44:194-202.

14. Youssef J, Juravle G, Youssef L, Woods A, Spence C. On the art and science of naming and plating food. Flavour. 2015;4:27.

15. Nassauer S: Using scent as a marketing tool, stores hope it-and shopperswill linger: How Cinnabon, Lush Cosmetics, Panera Bread regulate smells in stores to get you to spend more. The Wall Street Journal. 2014:May $20^{\text {th }}$. Downloaded from http://www.wsj.com/articles/SB1000142405270230346870 4579573953132979382 on 24/07/2015.
16. Vettel, P., \& Mitchum, R. (2007). Cancer strikes Alinea chef Grant Achatz in his prime. Chicago Tribune, July $24^{\text {th }}$. Downloaded from http:// www.chicagotribune.com/ct-grant-achatz-alinea-tongue-cancer-diagnosisstory.html on 30/10/2015.

17. Anonymous: Grant Achatz: The chef who couldn't taste. NPR, August $29^{\text {th }}$, 2011. Downloaded from http://www.npr.org/2011/08/29/139786504/grantachatz-the-chef-who-couldnt-taste on 29/10/2015.

18. Shahin J: Smoke signals: Use hay to smoke indoors. The Washington Post. 2011:January $18^{\text {th }}$. Downloaded from http://www.washingtonpost.com/wpdyn/content/article/2011/01/18/AR2011011802465.html on 17/08/2015.

19. Bloom D: (2014). Revolutionary new fork that adds own flavour to each mouthful is the latest foodie gadget to hit the market. Daily Mail Online, $23^{\text {rd }}$ March. Downloaded from http://www.dailymail.co.uk/sciencetech/ article-2587272/Revolutionary-new-fork-adds-flavour-mouthful-latest-foodiegadget-hit-market.html on 05/11/2014.

20. Spence C, Piqueras-Fiszman B. The perfect meal: the multisensory science of food and dining. Oxford: Wiley-Blackwell; 2014.

21. McGee H: On food and cooking: the science and lore of the kitchen (rev. ed.). New York, NY: Scribner, 1984/2004.

22. Michel C, Velasco C, Gatti E, Spence C. A taste of Kandinsky: assessing the influence of the visual presentation of food on the diner's expectations and experiences. Flavour. 2014;3:7.

23. Berghaus G. The futurist banquet: Nouvelle Cuisine or performance art? New Theatre Quarterly. 2001;17(1):3-17.

24. Weiss AS. Feast and folly: cuisine, intoxication and the poetics of the sublime. Albany: State University of New York Press; 2002.

25. Blumenthal H. The big Fat Duck cookbook. London: Bloomsbury; 2008.

26. Gordinier J: Puzzling death of Chicago's whirlwind chef, Homaro Cantu. The New York Times. 2015:April $17^{\text {th }}$. Downloaded from http://www.nytimes. com/2015/04/18/dining/trying-to-make-sense-of-homaro-cantusdeath.html?_r=0 on 17/08/2015.

27. Vettel P. Good Eating's fine dining in Chicago. Chicago: Agate Digital; 2013.

28. Crossley L: How an ounce of saffron is more expensive than gold: Cultivation of exotic spice returns to Essex for the first time in 200 years. The Daily Mail Online. 2014: $6^{\text {th }}$ November. Downloaded from http://www.dailymail.co.uk/ news/article-2823029/How-ounce-saffron-expensive-gold-Cultivation-exoticspice-returns-Essex-time-200-years.html on 19/08/2015.

29. Anonymous: 2009a Dinner for the muted senses - a food art workshop for five (or more) senses in a restaurant setup -workshop / event (2009). Downloaded from http://www.ueda.n//index.php?option=com_content\&view=category\& layout=blog\&id=111\&ltemid=793\&lang=en on 17/08/2009.

30. Vines R: London chef Heston Blumenthal re-creates his Fat Duck down under: Review. Bloomberg Business 2015:February 13 $3^{\text {th }}$. Downloaded from http://www.bloomberg.com/news/articles/2015-02-13//ondon-chef-hestonblumenthal-re-creates-his-fat-duck-down-under-review on 19/08/2015.

31. Anonymous: Delicious science. Harvard Mag. 2012:14 $4^{\text {th }}$ September. Downloaded from http://harvardmagazine.com/2012/09/delicious-science on $14 / 09 / 15$.

32. Gonzalez L. Ultraviolet by Chef Paul Pairet incorporates thematic video and perfumed air into his dining experience. 2013. Available at http:// www.psfk.com/2013/05/multisensory-dining-sight-sound-smells.html (accessed February 2014).

33. Gopnik A: Sweet revolution. The New Yorker. 2011:January 3. Downloaded from http://www.newyorker.com/reporting/2011/01/03/ 110103fa_fact_gopnik on 23/08/2015.

34. Narumi T, Nishizaka S, Kajinami T, Tanikawa T, Hirose M. Augmented reality flavors: gustatory display based on edible marker and cross-modal interaction. In: Proceedings of the 2011 Annual Conference on Human Factors in Computing Systems (CH'11). 2011. p. 93-102.

35. Harris J: Scentee makes your phone smell like a cinnamon roll or Korean BBQ when you get a text. Los Angeles Times. 2013:October $31^{\text {st }}$. Downloaded from http://www.latimes.com/food/dailydish/la-ddsmartphone-smell-bacon-scentee-20131030-story.html on 17/08/2015.

36. Griner D: 'Wake up and smell the bacon' with free alarm gadget from Oscar Meyer. AdWeek. 2014:6 th $^{\text {th }}$ March. Downloaded from http:// www.adweek.com/adfreak/wake-and-smell-bacon-free-alarm-gadget-oscarmayer-156123 on 13/07/2015.

37. Spence C, Piqueras-Fiszman B. Technology at the dining table. Flavour. 2013;2:16.

38. Baxter J. The perfect meal: in search of the lost tastes of France. New York: HarperCollins; 2013. 
39. Dumas D: The secret world of the taste makers. The Independent. 2010:28 ${ }^{\text {th }}$ April. Downloaded from http://www.independent.co.uk/life-style/food-anddrink/features/the-secret-world-of-the-taste-makers-1955989.html on 21/08/ 2015.

40. Wainwright O: Scentography: the camera that records your favourite smells. The Guardian. 2013:June $28^{\text {th }}$. Downloaded from http:// www.theguardian.com/artanddesign/architecture-design-blog/2013/jun/28/ scentography-camera-records-smells-memory on 21/08/2015.

41. Roithmann R, Cole P, Chapnik J, Shpirer I, Hoffstein V, Zamel N. Acoustic rhinometry in the evaluation of nasal obstruction. Laryngoscope. 1995;105:275-81.

42. Horning DE, Smith DJ, Kurtz DB, White T, Leopold DA. Effect of nasal dilators on nasal structures, sniffing strategies, and olfactory ability. Rhinology. 2001;39:84-7.

43. Hornung DE, Chin C, Kurtz DB, Kent PF, Mozell MM. Effect of nasal dilators on perceived odor intensity. Chem Senses. 1997;22:177-80.

44. Raudenbush B, Meyer B. Effect of nasal dilation on pleasantness, intensity and sampling behaviors of foods in the oral cavity. Rhinology. 2001;39:80-3.

45. Walsh V, Kulikowski J. Perceptual constancy: why things look as they do. Cambridge: Cambridge University Press; 1998.

46. Teghtsoonian R, Teghtsoonian M, Berglund B, Berglund U. Invariance of odor strength with sniff vigor: an olfactory analogue to size constancy. J Exp Psychol: Hum Perc Perform. 1978;4:144-52.

47. Le Magnen J: Étude des facteurs dynamiques de 1'excitation olfactive [Study of the dynamic factors in the stimulation of olfaction]. L'Annee Psychologique 1944-45:45-46;77-89.

48. Rehn T. Perceived odor intensity as a function of air flow through the nose. Sensory Processes. 1978;2:198-205.

49. Marinetti FT, Colombo L: La cucina futurista: Un pranzo che evitò un suicidio [The Futurist kitchen: A meal that prevented suicide]. Milan: Christian Marinotti Edizioni, 1930/1998.

50. Waugh E. Vile bodies. London: Chapman \& Hall; 1930.

51. Brickman S: The food of the future. The New Yorker. 2014:September $14^{\text {th }}$. Downloaded from http://www.newyorker.com/culture/culture-desk/foodfuture on 17/08/2015.

52. Hoyle B: Recipe for revolution takes diners back to the Futurists. The Times. 2008:28 January;23.

53. 50. Anonymous: futurism for foodies. Artnet. 2011:12 August. Available at http://www.artnet.com/magazineus/news/artnetnews/the-futuristcookbook.asp (accessed February 2014).

54. Barba ED: My cuisine is tradition in evolution. 2013. Downloaded from http://www.swide.com/food-travel/chef-interview/michelin-starred-chef-aninterview-with-massimo-bottura/2013/4/23 on 30/05/2013.

55. Griffiths S: The stick that makes cheap whiskey taste GOOD: Oak tool 'ages' and filters liquor in 24 hours - and it reduces the chance of you getting a hangover. Daily Mail Online. 2014:30 ${ }^{\text {th }}$ October. Downloaded from http:// www.dailymail.co.uk/sciencetech/article-2814342/The-stick-makes-cheapwhisky-taste-GOOD-Oak-tool-ages-filters-liquor-24-hours-reduces-chancegetting-hangover.html on 24/07/2015.

56. Ashley S: Synthetic food: better cooking through chemistry. 2013. Downloaded from http://www.pbs.org/wgbh/nova/next/physics/syntheticfood-better-cooking-through-chemistry/ on 23/08/2015.

57. This $\mathrm{H}$. La cuisine note à note en 12 questions souriantes [Note-by-note cuisine in 12 smiling questions]. Paris: Belin; 2012.

58. This H. Molecular gastronomy is a scientific discipline, and note by note cuisine is the next culinary trend. Flavour. 2013;2:1.

59. Spence $C$. The price of everything - the value of nothing? The World of Fine Wine. 2010;30:114-20.

60. Schafer SM, Colloca L, Wager TD. Conditioned placebo analgesia persists when subjects know they are receiving a placebo. J Pain. 2015;16:412-20.

61. Khatchadourian R: The taste makers. The New Yorker. 2009:23 $3^{\text {rd }}$ November. Downloaded from http://www.newyorker.com/magazine/2009/11/23/thetaste-makers on 24/07/2015.

62. Damrosch P. Service included: four-star secrets of an eavesdropping waiter. New York: William Morrow; 2008.

63. Porteous JD. Smellscape. Progress in Human Geography. 1985;9:356-78.

64. McCarthy B. Multi-source synthesis: an architecture of smell. Architect Design. 1996;121:66. (5/6):ii-v.

65. Spence C. Leading the consumer by the nose: On the commercialization of olfactory-design for thefood \& beverage sector. Flavour. 2015;4:31.

66. Fincks HT. The gastronomic value of odours. Contemp Rev. 1886;50:680-95.
67. Rozin P. "Taste-smell confusions" and the duality of the olfactory sense. Percept Psychophys. 1982:31:397-401.

68. Bojanowski V, Hummel T. Retronasal perception of odors. Physiol Behav. 2012;107:484-7.

69. Burdach KJ, Kroeze JHA, Koster EP. Nasal, retronasal, and gustatory perception: an experimental comparison. Percept Psychophy. 1984;36:205-8.

70. David E. Italian food. London: Barrie \& Jenkins; 1987.

71. Diaz ME. Comparison between orthonasal and retronasal flavour perception at different concentrations. Flavour Fragr J. 2004;19:499-504.

72. Pierce J, Halpern BP. Orthonasal and retronasal odorant identification based upon vapor phase input from common substances. Chem Senses. 1996;21:529-43.

73. Voirol E, Daget N. Comparative study of nasal and retronasal olfactory perception. Lebensm.-Wiss. Technol. 1986;19:316-9.

74. Small DM, Gerber JC, Mak YE, Hummel T. Differential neural responses evoked by orthonasal versus retronasal odorant perception in humans. Neuron. 2005;47:593-605

75. ISO Standard 5492. Terms relating to sensory analysis, International Organization for Standardization. Vienna: Austrian Standards Institute; 1992.

76. ISO Standard 5492. Terms relating to sensory analysis, International Organization for Standardization. Vienna: Austrian Standards Institute; 2008.

77. Smith AF, editor. The Oxford companion to American food \& drink. Oxford: Oxford University Press; 2007.

78. Whittle N: Chef talk: Simon Hopkinson. FT Magazine 2013:May 25/26;45.

79. Anonymous: 2009b Fat Duck wins award despite scare. BBC News, downloaded from http://news.bbc.co.uk/1/hi/england/berkshire/ 8208103.stm

80. Velasco C, Jones R, King S, Spence C. Assessing the influence of the multisensory environment on the whisky drinking experience. Flavour. 2013;2:23.

81. Polden J: From sun cream to freshly cut grass! Vending machine stocked with bottles of scented air brings the smell of summer to busy train station. Daily Mail Online. 2015:8 th August. Downloaded from http:// www.dailymail.co.uk/travel/travel_news/article-3187183/From-sun-creamfreshly-cut-grass-Vending-machine-stocked-bottles-scented-air-brings-smellsummer-busy-train-station.html on 27/08/2015.

82. Buchanan, L. (2013). Chewing and swallowing are so yesterday: Harvard University professor David Edwards is making caffeine, vitamins, and food you ingest in a powdery blast. Downloaded from http://www.inc.com/ audacious-companies/leigh-buchanan/aerodesigns.html on 30/10/2015.

83. Koutsovoulou E: Chandler Burr: "Take your seat to a scent dinner". Fine Dining Lovers 2014:June 26. Downloaded from https://www.finedininglovers.com/ stories/chandler-burr-interview-scent-dinner/ on 20/07/2015.

84. Lobrano A: LA DAME DE PIC-Scents \& Sensibility, B/C+. 2012. Downloaded from http://www.alexanderlobrano.com/restaurant-reviews/la-dame-de-picscents-sensibility-b-c/ on 24/08/2015.

85. Huxley A. Brave new world. New York: Harper \& Row; 1932.

\section{Submit your next manuscript to BioMed Central and take full advantage of:}

- Convenient online submission

- Thorough peer review

- No space constraints or color figure charges

- Immediate publication on acceptance

- Inclusion in PubMed, CAS, Scopus and Google Scholar

- Research which is freely available for redistribution 